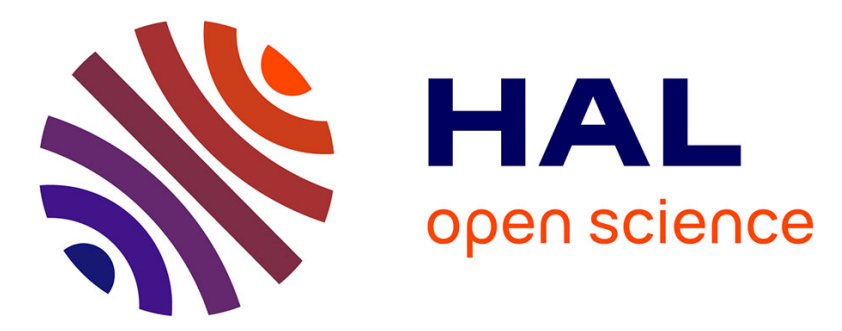

\title{
Increasing levels of saliva alpha amylase in electrohypersensitive (EHS) patients
}

Soafara Andrianome, Laurent Hugueville, René de Seze, Brahim Selmaoui

\section{To cite this version:}

Soafara Andrianome, Laurent Hugueville, René de Seze, Brahim Selmaoui. Increasing levels of saliva alpha amylase in electrohypersensitive (EHS) patients. International Journal of Radiation Biology, 2017, 93 (8), pp.841-848. 10.1080/09553002.2017.1325971 . ineris-01863166

\section{HAL Id: ineris-01863166 \\ https://hal-ineris.archives-ouvertes.fr/ineris-01863166}

Submitted on 28 Aug 2018

HAL is a multi-disciplinary open access archive for the deposit and dissemination of scientific research documents, whether they are published or not. The documents may come from teaching and research institutions in France or abroad, or from public or private research centers.
L'archive ouverte pluridisciplinaire HAL, est destinée au dépôt et à la diffusion de documents scientifiques de niveau recherche, publiés ou non, émanant des établissements d'enseignement et de recherche français ou étrangers, des laboratoires publics ou privés. 
Increasing levels of saliva alpha amylase in electrohypersensitive (EHS) patients

Soafara Andrianome $e^{1,2}$, Laurent Hugueville ${ }^{3}$, René de Seze ${ }^{1,2}$ and Brahim Selmaoui ${ }^{1,2^{*}}$

${ }^{1}$ Institut National de l'Environnement Industriel et des Risques (INERIS), Department of Experimental Toxicology, Verneuil-en-Halatte, France ;

${ }^{2}$ Université de Picardie Jules Verne, Peritox-Laboratoire de Périnatalité et Risques Toxiques UMR-I-01 Unité mixte INERIS, Amiens France ;

${ }^{3}$ Centre National de la Recherche Scientifique, Centre MEG-EEG, CRICM et CENIR, UMR 7225, Paris, France

*Email: brahim.selmaoui@ineris.fr 


\section{Increasing levels of saliva alpha amylase in electrohypersensitive (EHS) patients}

\section{Abstract}

The purpose: The objective of this study was to assess the level of various salivary and urinary markers of patients with EHS and to compare them with those of the healthy control group. Materials and methods: We analyzed samples from 30 EHS individuals and a matched control group of 25 individuals (non EHS) aged between 22 and 66. We quantified cortisol both in saliva and urine, alpha amylase (sAA), immunoglobulin A and C Reactive Protein levels in saliva and neopterin in urine (uNeopterin).

Results: sAA was found to be significantly higher $(\mathrm{p}<0.005)$ in the EHS group. uNeopterin and sAA analysis showed a significant difference based on the duration of EHS.

Conclusion: Higher level of sAA in EHS participants may suggest that the sympathetic adrenal medullar system is activated. However, most of the analyzed markers of the immune system, sympathetic activity and circadian rhythm did not vary significantly in EHS group. There is a trend to the higher levels of some variables in subgroups according to the EHS duration.

Keywords: IEI-EMF; EMF; alpha amylase; markers; symptoms; electromagnetic fields; environmental illness; saliva 


\section{Introduction}

A rapid development of technologies has increased the number of electromagnetic field (EMFs) sources. These include extremely low frequencies (ELF) and radiofrequencies (RF). While the debate is still focused on any potential public health impact due to their EMF emissions, some individuals report having symptoms that they relate to EMF exposure (Bergqvist U. and Vogel E. 1997). This sensitivity to EMF has been termed "electromagnetic hypersensitivity" (EHS). These non-specific symptoms include dermatological symptoms (redness, tingling and burning sensations), as well as neurasthenic and vegetative symptoms (fatigue, tiredness, concentration difficulties, dizziness, nausea, heart palpitation and digestive disturbances) (Eltiti et al. 2007). These symptoms are not part of any recognized syndrome. Therefore, and due to the fact that these symptoms are medically unexplained, the world health organization termed this sensitivity as Idiopathic Environmental Intolerance (IEI) attributed to electromagnetic fields (EMF)(Mild KH et al. 2006).

Despite the lack of scientific basis to objectively link EHS symptoms to EMF exposure, these symptoms and associated suffering certainly remain real and can vary widely in term of severity. Whatever the cause, EHS impacts on the quality of life of sufferers. So far, there are no clear diagnostic criteria, and no medical diagnosis has been validated. Therefore, physicians find themselves unarmed when facing patients.

The last decade has also been marked with rare involvement of EHS participants to research in this field. Many studies have suffered from this difficulty of recruitment, and EHS enrollment remains as particular challenge.

In view of the above and despite this challenge of volunteer recruitment, our work aimed to look for biochemical markers in a population suffering from electrohypersensitivity in the hope of bringing new elements that could help diagnosis. In this regard, some variables of the endocrine 
and immune systems and of sympathetic activity will be analyzed and compared to a non electrohypersensitive population (control). Our hypothesis is that electrohypersensitive patients might have a different biological profile than the control.

\section{Methods}

\section{Participants}

After approval from the regional French ethics committee "Comité de protection des personnes (CPP) Nord Ouest CHU Amiens, France (CPP, 2014/8)", 30 adults reporting EHS across France and 25 control individuals were recruited for this study. Individuals declaring being electrohypersensitive participated in the study. EHS patients (23 females and 7 males) and controls (21 females and 4 males) were aged between 22 and 63 (mean age: $47 \pm 9$ ) and 22 to 66 (mean age: $46 \pm 10$ ) respectively.

Controls and the EHS group were matched for age, sex and body mass Index (BMI). They were recruited by advertising in self-help blogs and hospital listservs or by traditional word of mouth. The EHS group was selected according to the inclusion criteria from participants who completed a questionnaire of hypersensitivity conducted by the research group before testing.

Inclusion criteria for the EHS group were an attribution of experienced symptom(s) to an electromagnetic source and an absence of acute psychiatric disorders, such as acute depressive or paranoid psychosis. Exclusion criteria for participants were the presence of chronic illness and the consumption of antibiotics, anti-inflammatory agents or any other supplements that may interfere with the biological assessments.

Participants were instructed to abstain from consuming alcohol and coffee for $24 \mathrm{~h}$ before and during each experimental session. They were also advised not to brush their teeth and not to exercise for at least an hour before sample collection. 
Before entering the study, all participants gave written, informed consent to participate in the study. Used methods were carried out in accordance with the approved guidelines. EHS participants were from different regions of France and were reimbursed for their travel fees, and all participants received financial compensation for their participation. From the questionnaire filled out by the participants, we extracted the duration of their sensitivity.

\section{Experimental protocol}

The first part of the experiment took place at the participant's home. Saliva samples were collected with salivettes@ tubes and a cotton plug (Sarstedt Nümbrecht, Germany) previously sent to the participants. Instructions were given on how and when to collect the saliva. Samples were self-collected on the day prior the experiment: one sample before bedtime and another one in the morning, just after waking up.

On the day of the experiment, participants came to the laboratory around 09:00 and spent their waking time in the laboratory. Participants were seated in a comfortable armchair inside an electrically shielded room with very low background fields. EMF levels were measured by a personal exposimeter, Satimo EME Spy 140 model. Newspapers, magazines and books were provided. From $10 \mathrm{~h} 00$ to $1 \mathrm{~h} 30$ and from $14 \mathrm{~h} 00$ to $16 \mathrm{~h} 30$, saliva was collected every $30 \mathrm{~min}$. The last saliva collection (16:30) was performed immediately after recording the electrodermal activity in response to auditory stimuli (results not shown).

In parallel, total urine was collected during the night from 20:00 to wake up time as the night fraction and from wake-up time to $16 \mathrm{~h} 30$ as the day-time fraction. More details of the study protocol are available in (Andrianome et al. 2016). 


\section{Sample collection, immunoassay and enzymatic protocols}

After rinsing their mouth with water thoroughly, participants collected saliva for over 3 min with a cotton plugged salivette. Salivettes were immediately kept in an icebox. After transportation to the laboratory, the tubes were centrifuged ( $2 \mathrm{~min}, 3000 \mathrm{rpm})$ and stored without preservatives at $-20^{\circ} \mathrm{C}$ until analysis. Urine fractions were aliquoted in appropriate tubes and stored at $-20^{\circ} \mathrm{C}$ until analysis.

The manufacturer's recommended protocols for saliva were used without modification for saliva cortisol, Immunoglobuline A (sIgA), C-reactive protein (CRP) (Salimetrics, State College, PA) and saliva alpha amylase (sAA) (IBL, Hamburg, Germany). For urine, protocols of neopterin

(IBL, Hamburg, Germany), creatinine (Enzo Life Sciences, Framingdate, NY) and cortisol (Arbor assay, MI) were applied.

Analyses were performed on all 12-points for saliva collected for cortisol, IgA and sAA while sCRP analyses were performed only on two points: 10:00 and 16:30.

All samples were tested in duplicate, and the average of duplicates was used as the final value.

\section{Statistical analysis}

Data were analyzed with SPSS statistical software, IBM SPSS Statistics for Windows, Version 20.0 (Armonk, NY: IBM Corp), and plotted by using Graphpad Prism, Version 5 (San Diego, $\mathrm{CA})$. Descriptive results of continuous variables were expressed in mean $\pm \mathrm{SD}$. We applied a two factors ANOVA for assessing time and group effects.

U Mann Whitney or Kruskall Wallis non-parametric tests were used to compare subgroups of EHS in terms of the median duration. Values were considered significantly different when $\mathrm{p}<$ 0.05. Correlation tests were performed by the Spearman correlation. 


\section{Results}

Results from EMF recording have showed that levels of EMF for radiofrequency were below the detection limit. The required number of EHS participants for our study was achieved with 30 individuals self-reporting EHS who fully agreed to participate to our study. This number can be considered as satisfactory given the difficulty of patient's enrollment.

Due to aberrant results for biochemical analysis from one EHS male, all data from this participant were not included in statistical analysis, leading to 29 EHS participants. The mean duration of EHS was 7.51 years (range: 1-19 years). Groups did not differ in terms of gender proportion (84\% of female participants in control group versus $79.31 \%$ in the EHS group, $\mathrm{p}=0.498)$, BMI $\left(22.80 \pm 2.60 \mathrm{~kg} / \mathrm{m}^{2}\right.$ in the control group, and $22.35 \pm 3.33 \mathrm{~kg} / \mathrm{m}^{2}$ in the EHS group, $\mathrm{p}=0.268$ ) and age ( $46 \pm 10$ years in the control group, and $47 \pm 9$ years in the EHS group, $\mathrm{p}=0.999$ ). No significant difference in proportion of smoker were found ( $24 \%$ in the control group, and $13.8 \%$ in the EHS group, $\mathrm{p}=0.307)$. In the control group, 24 participants were having an activity (96\%), and 24 participants in the EHS group $(82.75 \%),(\mathrm{p}=0.123)$.

\section{Salivary biomarkers}

The cortisol saliva concentrations in both groups were not significantly different. The cortisol secretion profiles were similar $(\mathrm{p}>0.05)$ with the lowest concentration at bedtime (control: mean: $0.04 \mu \mathrm{g} / \mathrm{dL}$; EHS mean: $0.06 \mu \mathrm{g} / \mathrm{dL}$ ) and the highest at waking time (control mean: 0.33 $\mu \mathrm{g} / \mathrm{dL}$; EHS mean: $0.29 \mu \mathrm{g} / \mathrm{dL})($ Fig.1).

Figure 1. Saliva level of cortisol in control (black line) and EHS (grey line) groups, data represent mean \pm SEM. Significant time effect $(\mathrm{p}<0.05)$ with typical morning peak (waking point). No significant effect of group was observed $(\mathrm{p}>0.05)$ 
sAA activity was significantly different $(\mathrm{p}<0.0001)$ between the control and EHS group. The EHS group showed a significantly higher level of sAA (Fig.2a).

ANOVA analysis showed that the IgA level in saliva was not significantly different between both groups but showed a significant time variation $(\mathrm{p}<0.0001)$ (Fig.2b). A peak of sIgA was reached in the control group at awakening $(106.53 \pm 44.04 \mu \mathrm{g} / \mathrm{ml})$ with a significant difference when compared to all the other time points. In the EHS group, no difference was disclosed between awakening sIgA levels and those of the other points $(\mathrm{p}>0.05)$.

Figure 2. Salivary concentration of alpha amylase (sAA) (a) and immunoglobuline A (IgA) (b) in the control (black line) and EHS group (grey line) during experimentation (from bedtime to 16.30). Data expressed as mean \pm SEM

- Significant difference between groups for $\underline{\mathrm{sAA}}(\mathrm{p}<0.0001)$

- Significant effect of time for $\underline{\mathrm{sAA}}(\mathrm{p}=0.0001)$ and $\operatorname{IgA}(\mathrm{p}<0.0001)$

sCRP levels showed a significant increase in the morning, when compared to the afternoon levels $(\mathrm{p}<0.0001)$. However, no significant difference could be detected between the EHS group and the control group (Fig.3).

Figure 3. Mean \pm SEM of salivary CRP in the control (black bars) and EHS group (grey bars)

\section{Saliva correlation with selected clinical parameters and EHS subgroup analysis}

For the EHS group, sAA levels were different between the male and female participants. Male participants expressed higher levels than female participants. sIgA and sCRP were negatively correlated with age at $\mathrm{r}=-0.135, \mathrm{p}=0.017$ and $\mathrm{r}=-0.36, \mathrm{p}=0.007$ respectively.

The mean of $\operatorname{sIg}$ A showed a tendency to be positively correlated with EHS duration $(\mathrm{r}=0.141, \mathrm{p}$ $=0.010)$; sAA was also slightly but positively correlated with EHS duration $(\mathrm{r}=0.254, \mathrm{p}<$ 0.001). 
According to the median of duration of EHS, which was seven years, there is no subgroup

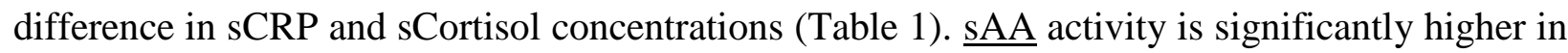
patients reporting EHS $\geq 7$ years for saliva collected at 10:00. Likewise, sIgA shows a difference between the control and EHS groups at bedtime.

\section{Urinary biomarkers}

Urinary cortisol and neopterin concentrations, adjusted to creatinine, did not show any significant difference between the control and EHS groups. Urine neopterin to creatinine concentrations were significantly higher for the morning fraction than for the night fraction for both groups $(\mathrm{p}<0.05)$ (Fig. 4).

Figure 4. Mean \pm SEM of urine cortisol:creatinine ratio (a) and neopterine:creatinine ratio (b) in control (black bars) and EHS group (grey bars). No significant effect of group, significant time effect for neopterine:creatinine ratio, $\mathrm{p}<0.05$ (b); abbreviations: UNCR: urinary neopterin to creatinine ratio.

\section{Urine biomarkers and EHS subgroup analysis}

According to the median duration of EHS, which is seven years, there is no difference in urinary cortisol levels between participants being EHS less than seven years and those being EHS more than seven years (Table 2). However, in the morning fraction of urine, a significant difference was found for neopterin between the control and EHS group and between the EHS subgroups. 


\section{Discussion}

This study was designed in an attempt to find out some biological markers that may differentiate EHS individuals from the rest of the population (non-EHS) and explain the occurrence of the atypical symptoms they complain about. In this regard, some markers of the immune, circadian and autonomic nervous systems were explored.

Among the markers analyzed, cortisol is considered as a reliable marker of the endogenous circadian oscillator (Haus E and Touitou Y. 1994) and as a primary biological indicator for stress reactions for the hypothalamic-pituitary-adrenal (HPA) axis (Kirschbaum \& Hellhammer 1989; Kirschbaum \& Hellhammer 1994). Our present work showed no significant differences in saliva cortisol levels between a group suffering from EHS and a control group. In light of the above, our results are in agreement with the literature and show a peak in the morning immediately after wake up and a trough around bedtime (Krieger 1975; Selmaoui \& Touitou 2003). Neither the cortisol peak in the morning nor the lowest values of the day (bedtime) were different between the two groups. This may suggest that the HPA axis is not affected in EHS patients. Additionally, the amount of cortisol in urine did not differ between both groups $(\mathrm{p}>0.05)$, confirming the finding of the saliva analysis.

Besides, the salivary enzyme $\alpha$-amylase has been proposed as a marker for the stress-induced activity of the sympathetic nervous system (SNS), or more precisely of the sympathetic adrenomedullary (SAM) system, which is also involved in the secretion of adrenaline and noradrenaline (Chatterton et al. 1996; Rohleder \& Nater 2009). Unlike cortisol, saliva alpha amylase levels were found to be significantly higher in the EHS group, in comparison to the control group. The question that arises here is whether this change in $\alpha$-amylase activity was a result of outside exposure to EMF or simply a consequence of chronic stress. 
The question whether EHS patients are stressed by various environmental/ biological factors other than EMF is at the center of various research. Nowadays, there are only few studies dealing with the EHS population and which are not so far conclusive. Some few studies have tried to find a link with other diseases or other environmental factors such as study by Palmquist et al. (2014) who found an overlap between 4 types of environmental intolerances: exposure to odorous/pungent chemicals, certain buildings, everyday sounds and EMFs. While some other authors (Rubin et al. 2010), proposed the presence of a "nocebo effects". In our population: no specific questionnaire about environmental stressing factors were presented. On the other hand, levels of cortisol do not indicate the presence of stress.

With regard to the biological stress system, one may wonder why only SAM has been activated and not the HPA axis if there are stress-related changes. It is known that these two physiological systems are independent in terms of neuronal circuits (Ulrich-Lai \& Herman 2009) and that they may react differently to stressors. Some results suggested that the responses of the HPA and SAM systems differ depending on the type of stressor (Maruyama et al. 2012). Moreover, salivary cortisol levels increase a few minutes after the initiation of stress (Droste et al. 2008; Takai et al. 2004), meaning that the HPA axis is relatively slower to respond while sAA levels are characterized by a rapid increase after a stress action, followed by a rapid decrease to normal levels after the cessation of the stressor (Speirs et al. 1974; Takai et al. 2004). However, in the present study, sAA levels were shown to be constantly elevated in EHS individuals, even during their stay (from $09 \mathrm{~h} 00$ to 16h30) in the EMF shielded room in our laboratory. The role of EMF on the increase of AA is still to be proven. However, our results indicated that EHS population seems to have higher levels of sAA than control group. And the cause of this increase is to be yet determined.

Moreover, a significant and positive correlation was shown between sAA levels and the duration of EHS. Indeed, the longer the duration of EHS, the higher the level of sAA. This may suggest 
that the longer they are EHS, the more they react. One may speculate that this could be due to a degraded system in patients presenting EHS for a long-time.

Besides, a study has shown that exposure to radiofrequency electromagnetic fields (RF-EMF) emitted by mobile phone base stations affected salivary $\alpha$-amylase in healthy participants (Augner et al. 2010). In addition, a study of people living next to phone base stations, selfdeclaring base-station neighbors (distance to base station $\leq 100$ meters), had higher levels of $\alpha$ amylase accompanied by a higher general strain (Augner \& Hacker 2009; Augner et al. 2010). This may suggest that people self-reporting EHS could share similarities with this population, but whether this is due to actual exposure to EMF or to other underlying factors is not clear. In our study, unfortunately, recordings of exposure field density before entering the study (outside the experimental lab) were not available.

Moreover, levels of IgA in saliva vary in response to physical and psychological stress through interactions with the autonomic nervous system (Tsujita \& Morimoto 1999; Bishop \& Gleeson 2009). Saliva IgA concentrations were found to be similar between the EHS population and the matched control group. However, we could observe a significant variation in the pattern of $\operatorname{IgA}$ between morning and afternoon. This is in accordance with previous studies showing that $\operatorname{IgA}$ patterns follow a circadian rhythm (Casale et al. 1983). Subgroup analysis showed that people declaring longer EHS had higher levels of IgA for bedtime collected saliva.

$\mathrm{C}$ reactive protein (CRP) is widely used as an inflammatory marker and could indicate bio inflammation of the body. High levels of serum CRP have been correlated to cardiovascular risks and other inflammatory or immune diseases (Tracy et al. 1997; Du Clos 2003). Recently, elevated levels of CRP and hsp70 have been detected in frequent users of mobile phones (Balakrishnan et al. 2014). In this cohort, concentrations of saliva CRP in the EHS group were 
not different from those of the control group, indicating the absence of an acute inflammatory process. Furthermore, highly sensitive CRP was higher in the morning than in the evening. This finding is compatible with results in healthy young adults (Izawa et al. 2013).

Neopterin in urine showed a light-dark variation in both groups, which corroborates previous findings (Garcia-Gonzalez et al. 2006). Surprisingly, subgroups analysis showed a variation according to the duration of the EHS effect. We found, in the day fraction of urine, a lower level of neopterin in patients reporting EHS for more than seven years, compared to those with shorter EHS. Little information is available on immune markers in EHS and on the immune effect of electromagnetic fields. Immune cells or cytokines were not modified under acute exposure to ELF magnetic fields (Selmaoui et al. 1996; Selmaoui et al. 2011) or GSM 900 MHz exposure (Tuschl et al. 2006). In an experiment with exposure to a GSM signal, neopterin was not modified in saliva (Radon et al. 2001). Other studies showed that acute exposure to ELF did not have an effect on blood concentrations of TSH, FSH, LH, testosterone, cortisol or neopterin (Gamberale et al. 1989; Selmaoui et al. 1996).

In our study, we used low tech and bloodless methods to analyze markers in the EHS population. Besides an accepted general method of collection (a cotton swab), all the stress-minimizing methods used here are shown to be appropriate in quantifying such markers.

Regarding the age of the EHS group, variability due to the age widths of participants was reduced by recruiting matched volunteers as far as possible. Besides this age characteristic, for a more powerful analysis and according to the subgroup exploration, a larger number of participants would be required for future studies.

Here, the classification of EHS subgroups according to the duration of their EHS can be a disputable point due to the declarative nature of this information. It could be understood that the 
determination of an exact timing of the triggering the syndrome may be an estimate without any known diagnostic. It could correspond here to the development of major symptoms or the occurrence of a special event. Here again, the lack of an existing diagnosis of EHS poses a serious problem.

A retrospective analysis of exposure and recording the lifetime information of participants could be an important issue in understanding EHS that could be coupled with such data. Until now, limited information about the mechanism of EHS is available, and few studies have explored the biological mechanism in EHS, though particular emphasis has been put on "provocation studies," which were not conclusive. In the absence of a known biological mechanism, the exploration of more markers involved in immunological activity could complete our study, without minimizing the complex interaction among symptoms, health concerns and risk perceptions in this particular population.

\section{Conclusions}

In summary, an exploration of selected and measurable markers of EHS was conducted in our study to understand this condition. Our finding indicates that markers of the circadian rhythm and immune system were not affected in EHS compared to non EHS individuals. Our results suggest different profiles of EHS according to the duration of the syndrome. Furthermore, the mechanism underlying the higher expression of $\alpha$-amylase should be focused on. These findings could be new elements in the understanding, explanation and comprehension of the physiopathology of EHS.

\section{Acknowledgements}

This project was financed by a grant from the French National Research Program for Environmental and Occupational Health of ANSES (Project $\mathrm{n}^{\circ} 2013-2-02$ ). Particular thanks to 
all volunteers for their participation. Thanks to Kelly Blazy and Maïté Hanot-Roy for their contribution on elisa analysis.

\section{Declaration of interest statement}

The authors report no declarations of interest. 


\section{References}

Andrianome S, Hugueville L, de Seze R, Hanot-Roy M, Blazy K, Gamez C, Selmaoui B. 2016. Disturbed sleep in individuals with Idiopathic environmental intolerance attributed to electromagnetic fields (IEIEMF): Melatonin assessment as a biological marker. Bioelectromagnetics.

Augner C, Hacker GW. 2009. Are people living next to mobile phone base stations more strained? Relationship of health concerns, self-estimated distance to base station, and psychological parameters. Indian J Occup Environ Med. 13:141-145.

Augner C, Hacker GW, Oberfeld G, Florian M, Hitzl W, Hutter J, Pauser G. 2010. Effects of exposure to GSM mobile phone base station signals on salivary cortisol, alpha-amylase, and immunoglobulin A. Biomed Environ Sci BES. 23:199-207.

Balakrishnan K, Murali V, Rathika C, Manikandan T, Malini RP, Kumar RAS, Krishnan M. 2014. Hsp70 is an independent stress marker among frequent users of mobile phones. J Environ Pathol Toxicol Oncol Off Organ Int Soc Environ Toxicol Cancer. 33:339-347.

Bergqvist U., Vogel E. 1997. Possible health implication of subjective symptoms and electromagnetic fields. A report by a European group of experts for the European Commission, DG V. Solna (Sweden): National Institute for Working Life; 1997. [place unknown].

Bishop NC, Gleeson M. 2009. Acute and chronic effects of exercise on markers of mucosal immunity. Front Biosci Landmark Ed. 14:4444-4456.

Casale G, Marinoni GL, d'Angelo R, de Nicola P. 1983. Circadian rhythm of immunoglobulins in aged persons. Age Ageing. 12:81-85.

Chatterton RT Jr, Vogelsong KM, Lu YC, Ellman AB, Hudgens GA. 1996. Salivary alpha-amylase as a measure of endogenous adrenergic activity. Clin Physiol Oxf Engl. 16:433-448.

Droste SK, de Groote L, Atkinson HC, Lightman SL, Reul JMHM, Linthorst ACE. 2008. Corticosterone levels in the brain show a distinct ultradian rhythm but a delayed response to forced swim stress. Endocrinology. 149:3244-3253.

Du Clos TW. 2003. C-reactive protein as a regulator of autoimmunity and inflammation. Arthritis Rheum. 48:1475-1477.

Eltiti S, Wallace D, Zougkou K, Russo R, Joseph S, Rasor P, Fox E. 2007. Development and evaluation of the electromagnetic hypersensitivity questionnaire. Bioelectromagnetics. 28:137-151.

Gamberale F, Olson BA, Eneroth P, Lindh T, Wennberg A. 1989. Acute effects of ELF electromagnetic fields: a field study of linesmen working with $400 \mathrm{kV}$ power lines. Br J Ind Med. 46:729-737.

Garcia-Gonzalez MJ, Dominguez-Rodriguez A, Abreu-Gonzalez P. 2006. Diurnal variations in serum neopterin levels are associated with the pineal hormone melatonin circadian rhythm in healthy human subjects. J Pineal Res. 40:288-289.

Haus E and Touitou Y. 1994. Chronobiology in laboratory medicine.

Izawa S, Miki K, Liu X, Ogawa N. 2013. The diurnal patterns of salivary interleukin-6 and C-reactive protein in healthy young adults. Brain Behav Immun. 27:38-41.

Kirschbaum C, Hellhammer DH. 1989. Salivary cortisol in psychobiological research: an overview. Neuropsychobiology. 22:150-169. 
Kirschbaum C, Hellhammer DH. 1994. Salivary cortisol in psychoneuroendocrine research: recent developments and applications. Psychoneuroendocrinology. 19:313-333.

Krieger DT. 1975. Rhythms of ACTH and corticosteroid secretion in health and disease, and their experimental modification. J Steroid Biochem. 6:785-791.

Maruyama Y, Kawano A, Okamoto S, Ando T, Ishitobi Y, Tanaka Y, Inoue A, Imanaga J, Kanehisa M, Higuma H, et al. 2012. Differences in salivary alpha-amylase and cortisol responsiveness following exposure to electrical stimulation versus the Trier Social Stress Tests. PloS One. 7:e39375.

Mild KH, Repacholi M, van Deventer E, Ravazzani P. 2006. Electromagnetic hypersensitivity, in: proceedings of the International Workshop on EMF Hypersensitivity,Prague, Czech Republic, October 25-27, 2004, World Health Organization, 2006.

Palmquist E, Claeson A-S, Neely G, Stenberg B, Nordin S. 2014. Overlap in prevalence between various types of environmental intolerance. Int J Hyg Environ Health. 217:427-434.

Radon K, Parera D, Rose DM, Jung D, Vollrath L. 2001. No effects of pulsed radio frequency electromagnetic fields on melatonin, cortisol, and selected markers of the immune system in man. Bioelectromagnetics. 22:280-287.

Rohleder N, Nater UM. 2009. Determinants of salivary alpha-amylase in humans and methodological considerations. Psychoneuroendocrinology. 34:469-485.

Rubin GJ, Nieto-Hernandez R, Wessely S. 2010. Idiopathic environmental intolerance attributed to electromagnetic fields (formerly "electromagnetic hypersensitivity"): An updated systematic review of provocation studies. Bioelectromagnetics. 31:1-11.

Selmaoui B, Bogdan A, Auzeby A, Lambrozo J, Touitou Y. 1996. Acute exposure to $50 \mathrm{~Hz}$ magnetic field does not affect hematologic or immunologic functions in healthy young men: a circadian study. Bioelectromagnetics. 17:364-372.

Selmaoui B, Lambrozo J, Sackett-Lundeen L, Haus E, Touitou Y. 2011. Acute exposure to 50-Hz magnetic fields increases interleukin-6 in young healthy men. J Clin Immunol. 31:1105-1111.

Selmaoui B, Touitou Y. 2003. Reproducibility of the circadian rhythms of serum cortisol and melatonin in healthy subjects: a study of three different 24-h cycles over six weeks. Life Sci. 73:3339-3349.

Speirs RL, Herring J, Cooper WD, Hardy CC, Hind CR. 1974. The influence of sympathetic activity and isoprenaline on the secretion of amylase from the human parotid gland. Arch Oral Biol. 19:747-752.

Takai N, Yamaguchi M, Aragaki T, Eto K, Uchihashi K, Nishikawa Y. 2004. Effect of psychological stress on the salivary cortisol and amylase levels in healthy young adults. Arch Oral Biol. 49:963-968.

Tracy RP, Lemaitre RN, Psaty BM, Ives DG, Evans RW, Cushman M, Meilahn EN, Kuller LH. 1997. Relationship of C-reactive protein to risk of cardiovascular disease in the elderly. Results from the Cardiovascular Health Study and the Rural Health Promotion Project. Arterioscler Thromb Vasc Biol. $17: 1121-1127$.

Tsujita S, Morimoto K. 1999. Secretory IgA in saliva can be a useful stress marker. Environ Health Prev Med. 4:1-8.

Tuschl H, Novak W, Molla-Djafari H. 2006. In vitro effects of GSM modulated radiofrequency fields on human immune cells. Bioelectromagnetics. 27:188-196. 
Ulrich-Lai YM, Herman JP. 2009. Neural regulation of endocrine and autonomic stress responses. Nat Rev Neurosci. 10:397-409.

\section{Figure captions}

Figure 1. Saliva level of cortisol in control (black line) and EHS (grey line) groups, data represent mean \pm SEM. Significant time effect $(p<0.05)$ with typical morning peak (waking point). No significant effect of group was observed $(p>0.05)$

Figure 2. Salivary concentration of $\alpha$-amylase (a) and $\operatorname{IgA}$ (b) in the control (black line) and EHS group (grey line) during experimentation (from bedtime to 16.30). Data expressed as mean \pm SEM

- Significant difference between groups for $\alpha$-amylase $(\mathrm{p}<0.0001)$

- Significant effect of time for $\alpha$-amylase $(\mathrm{p}=0.0001)$ and $\operatorname{IgA}(\mathrm{p}<0.0001)$

Figure 3. Mean \pm SEM of salivary CRP in the control (black bars) and EHS group (grey bars)

Figure 4. Mean \pm SEM of urine cortisol:creatinine ratio (a) and neopterine:creatinine ratio (b) in control (black bars) and EHS group (grey bars). No significant effect of group, significant time effect for neopterine:creatinine ratio, $\mathrm{p}<0.05$ (b); abbreviations: UNCR: urinary neopterin to creatinine ratio. 


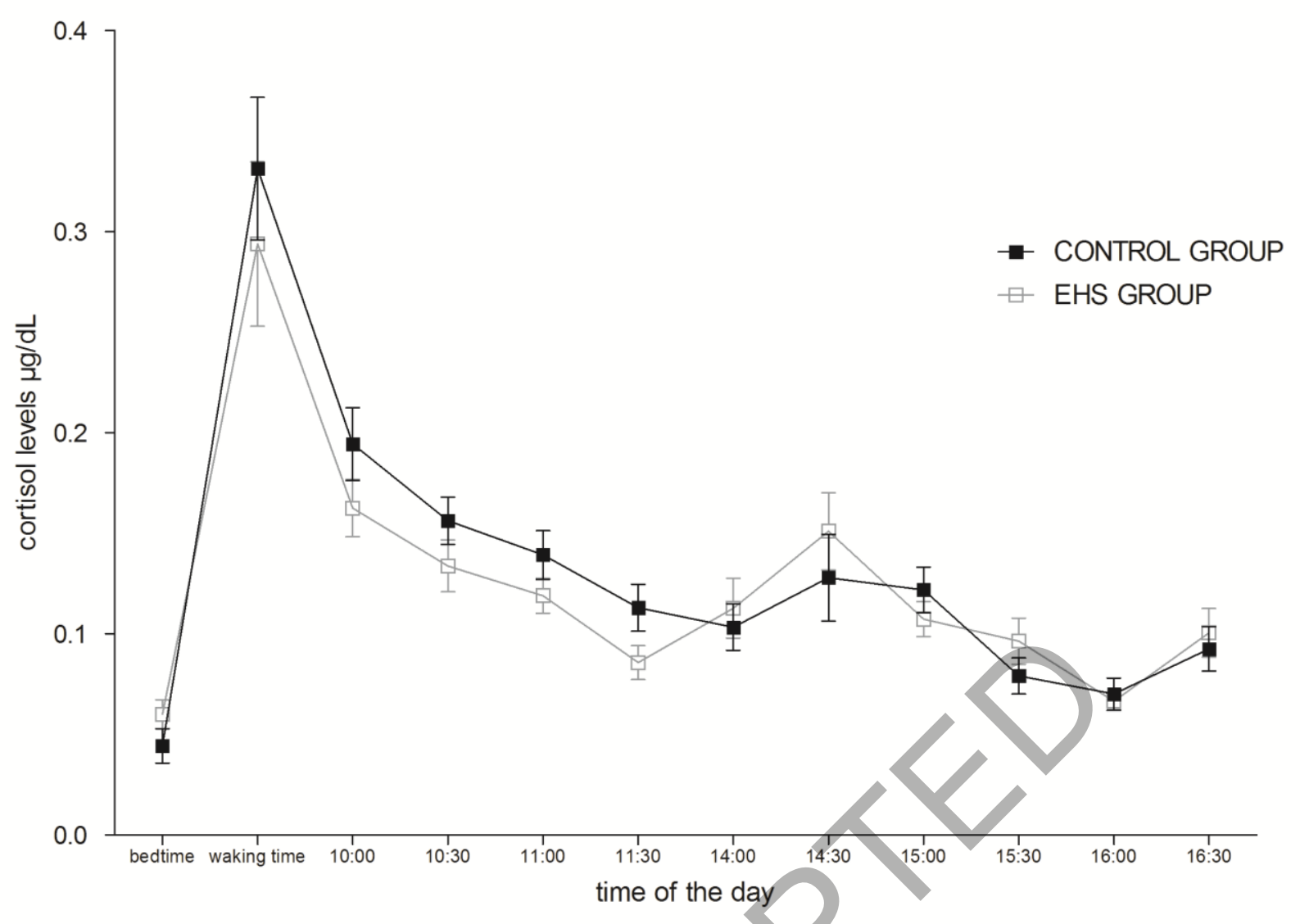


$2 a$

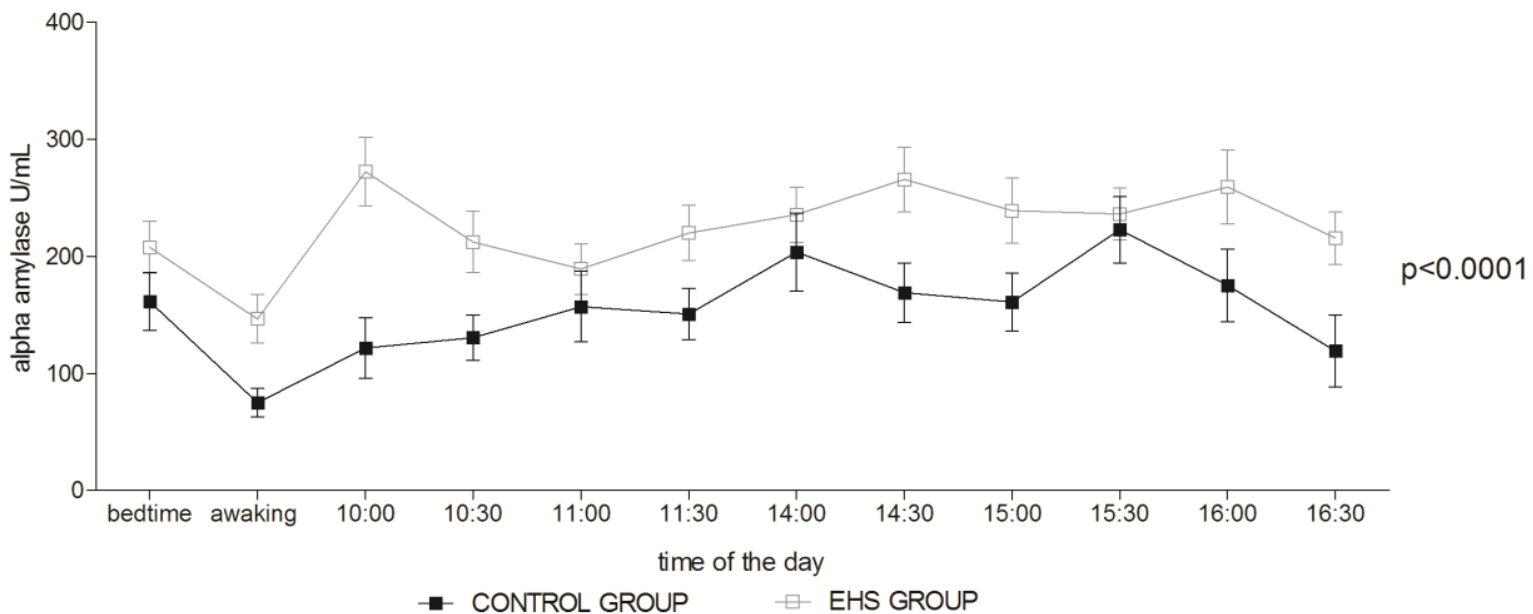

$2 b$

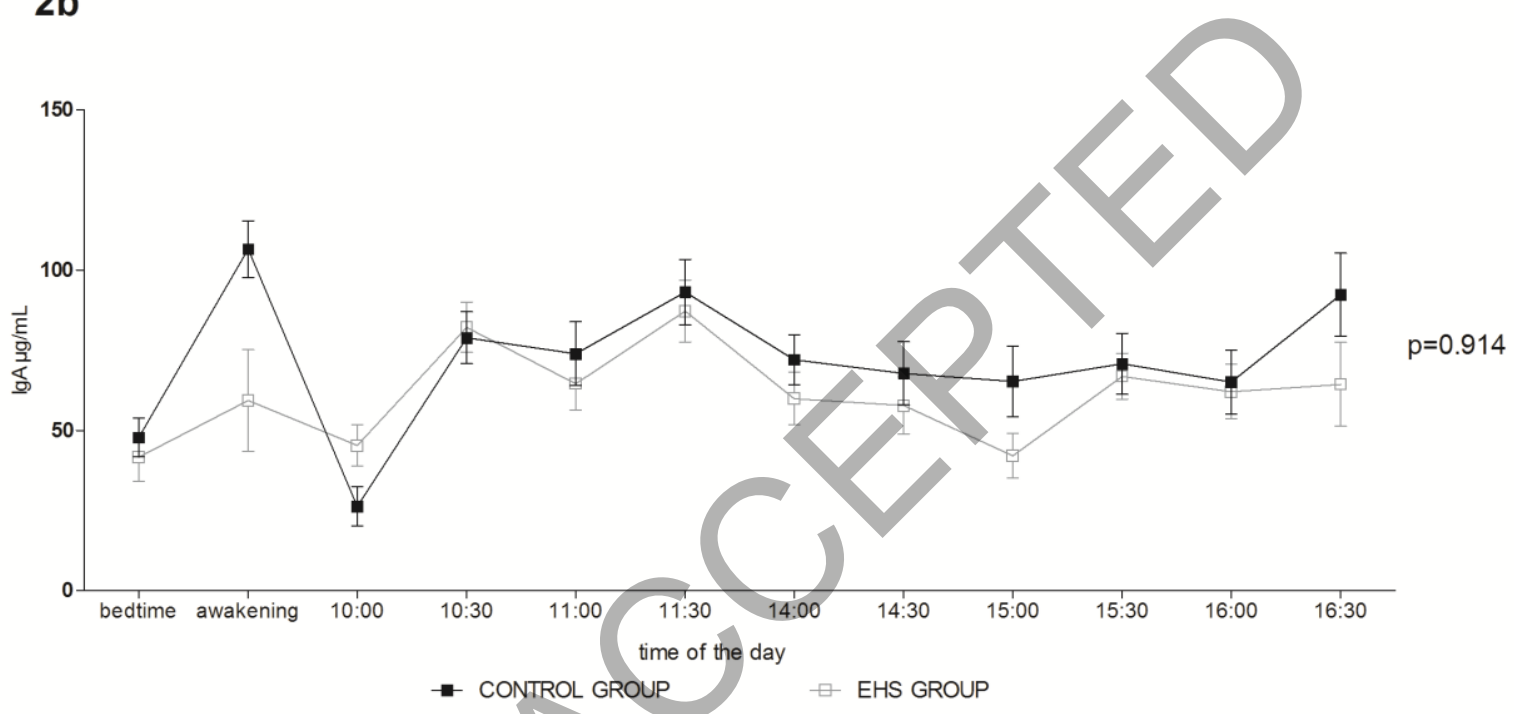




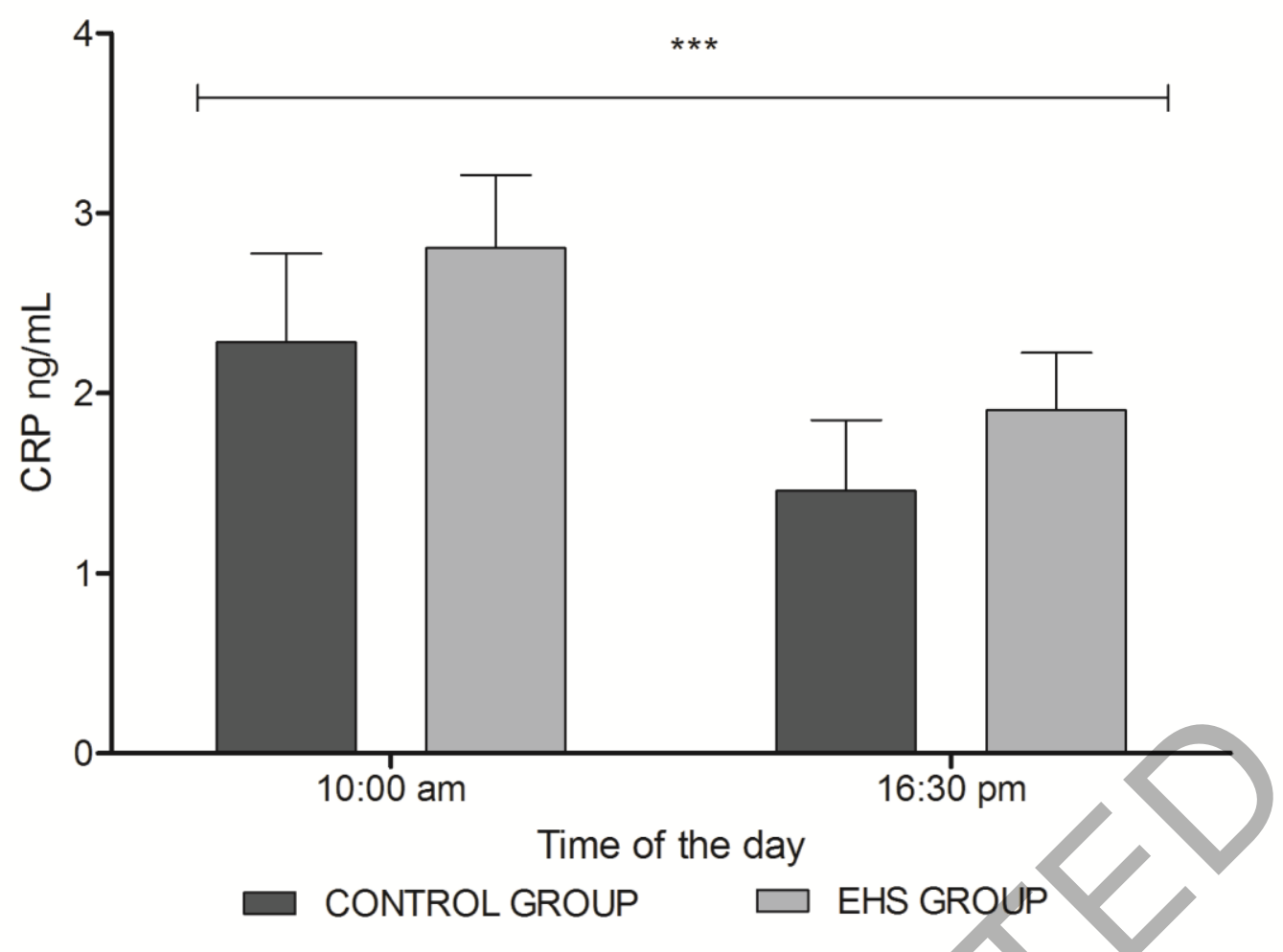




\section{$4 a$}
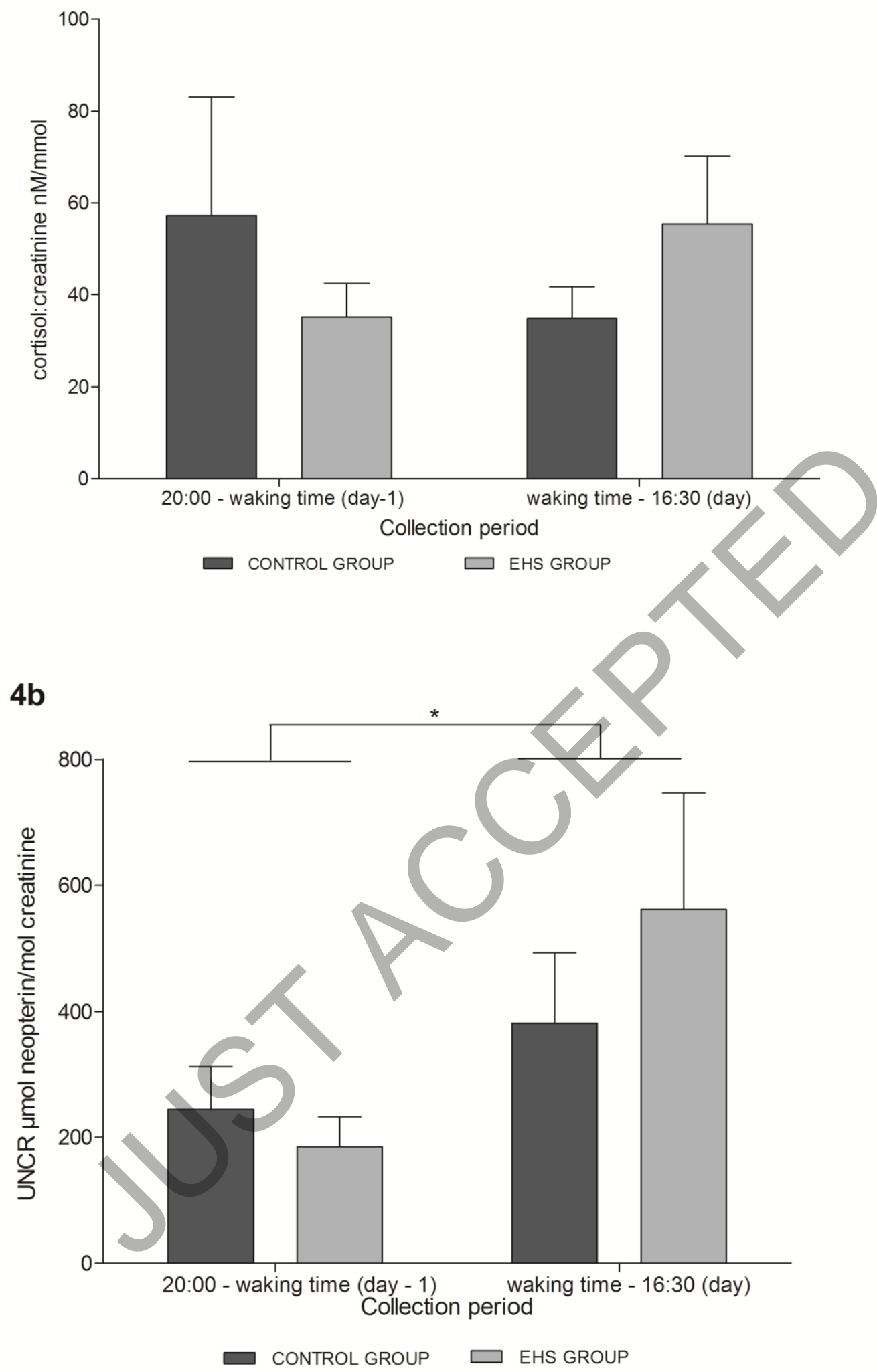
Table 1. Demographic characteristics and levels of markers in control and subgroups of EHS based on EHS duration (median duration $=7$ years) in saliva collected at night, wake up, 10:00, and 16:30

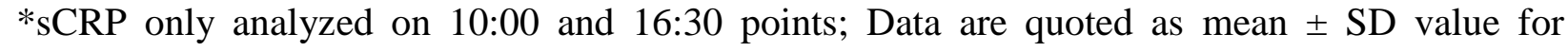
continuous variables, or number;

symbols: $\$ \mathrm{p}<0.05 ; \S \mathrm{p}<0.01$

\begin{tabular}{|c|c|c|c|c|c|}
\hline & Control group & $\begin{array}{l}\text { EHS } \\
\text { duration <7 } \\
\text { years }(A)\end{array}$ & $\begin{array}{l}\text { EHS } \\
\text { duration } \geq 7 \\
\text { years }(B)\end{array}$ & $\begin{array}{l}P \text { - } \\
\text { values } \\
\text { (A vs. } \\
\text { B) }\end{array}$ & $\begin{array}{l}\text { Global P* } \\
\text { values }\end{array}$ \\
\hline $\mathrm{n}$ & 25 & 17 & 12 & - & - \\
\hline Mle & 4 & 3 & 3 & - & - \\
\hline Female & 21 & 15 & 8 & 0.494 & - \\
\hline Age, years & 46.24 & 47.50 & 44.82 & 0.674 & 0.942 \\
\hline BMI, $k g / m^{2}$ & $22.80 \pm 2.60$ & $22.11 \pm 2.54$ & $21.91 \pm 3.52$ & 0.707 & 0.470 \\
\hline \multicolumn{6}{|l|}{ sCRP } \\
\hline$* 10: 00 \mathrm{ng} / \mathrm{mL}$ & $2.74 \pm 0.90$ & $2.56 \pm 1.11$ & $3.09 \pm 0.88$ & 0.173 & 0.419 \\
\hline *16:30 ng/mL & $1.75 \pm 0.90$ & $1.90 \pm 0.73$ & $2.10 \pm 0.90$ & 0.674 & 0.489 \\
\hline \multicolumn{6}{|l|}{ cortisol } \\
\hline bedtime $\mu g / d L$ & $0.041 \pm 0.041$ & $0.061 \pm 0.047$ & $0.049 \pm 0.028$ & 0.777 & 0.333 \\
\hline awakening $\mu g / d L$ & $0.331 \pm 0.178$ & $0.279 \pm 0.194$ & $0.299 \pm 0.250$ & 0.698 & $0.049 \ddagger$ \\
\hline $10: 00 \mu g / d L$ & $0.187 \pm 0.095$ & $0.152 \pm 0.079$ & $0.186 \pm 0.074$ & 0.227 & 0.298 \\
\hline $16: 30 \mu \mathrm{g} / \mathrm{dL}$ & $0.074 \pm 0.058$ & $0.095 \pm 0.075$ & $0.092 \pm 0.052$ & 0.744 & 0.584 \\
\hline \multicolumn{6}{|l|}{ sAA } \\
\hline bedtime $\mathrm{U} / \mathrm{mL}$ & $161.26 \pm 124.07$ & $182.14 \pm 125.07$ & $240.10 \pm 108.44$ & 0.166 & 0.124 \\
\hline awakening $\mathrm{U} / \mathrm{mL}$ & $75.12 \pm 60.45$ & $146.29 \pm 140.12$ & $146.82 \pm 62.68$ & 0.501 & $0.014 \ddagger$ \\
\hline $10: 00 \mathrm{U} / \mathrm{mL}$ & $121.62 \pm 129.84$ & $185.67 \pm 109.54$ & $337.50 \pm 163.42$ & $0.043 \ddagger$ & $0.007 \S$ \\
\hline $16: 30 \mathrm{U} / \mathrm{mL}$ & $119.20 \pm 152.86$ & $208.79 \pm 142.71$ & $226 \pm 89.71$ & 0.781 & $0.033 \ddagger$ \\
\hline \multicolumn{6}{|l|}{ IgA } \\
\hline bedtime $\mu g / m L$ & $47.74 \pm 30.32$ & $30.41 \pm 37.86$ & $57.46 \pm 39.04$ & $0.03 \ddagger$ & $0.034 \ddagger$ \\
\hline awakening $\mu \mathrm{g} / \mathrm{mL}$ & $106.54 \pm 44.04$ & $55.70 \pm 89.12$ & $64.29 \pm 82.56$ & 0.913 & $0.003 \S$ \\
\hline $10: 00 \mu \mathrm{g} / \mathrm{mL}$ & $26.20 \pm 31.06$ & $53.57 \pm 33.13$ & $33.38 \pm 34.90$ & 0.073 & $0.025 \ddagger$ \\
\hline $16: 30 \mu \mathrm{g} / \mathrm{mL}$ & $92.27 \pm 64.62$ & $52.74 \pm 36.67$ & $77.90 \pm 96.56$ & 0.781 & 0.061 \\
\hline
\end{tabular}


Table 2. Biochemical urinary characteristics of the study population: controls $(n=25)$ and the two subgroups (based on the median duration of EHS), data are quoted as mean \pm SD

\begin{tabular}{|c|c|c|c|c|c|}
\hline & $\begin{array}{l}\text { Control } \\
(n=25)\end{array}$ & $\begin{array}{l}\text { EHS duration }<7 \\
\text { years }(A)(n=17)\end{array}$ & $\begin{array}{l}\text { EHS duration } \geq 7 \\
\text { years }(B)(n=12)\end{array}$ & $\begin{array}{l}P \quad(A \\
\text { vs. } B)\end{array}$ & Global P \\
\hline \multicolumn{6}{|c|}{ Night fraction (20:00 to awakening) } \\
\hline $\begin{array}{l}\text { Cortisol:creatinin } \\
(\mathrm{nmol} / \mathrm{mmol})\end{array}$ & $\begin{array}{l}54.90 \pm \\
12.14\end{array}$ & $38.85 \pm 47.63$ & $34.18 \pm 33.33$ & 0.914 & 0.989 \\
\hline $\begin{array}{l}\text { Neopterin:creatinin } \\
(\mu \mathrm{mol} / \mathrm{mol})\end{array}$ & $\begin{array}{l}223.82 \pm \\
314.10\end{array}$ & $229.40 \pm 322.17$ & $107.15 \pm 81.53$ & 0.377 & 0.153 \\
\hline \multicolumn{6}{|c|}{ Day fraction (awakening to 16:30) } \\
\hline $\begin{array}{l}\text { Cortisol:creatinin } \\
(\mathrm{nmol} / \mathrm{mmol})\end{array}$ & $\begin{array}{l}33.51 \\
33.64\end{array}$ & $57.10 \pm 10.33$ & $52.47 \pm 53.71$ & 603 & 0.368 \\
\hline $\begin{array}{l}\text { Neopterin:creatinin } \\
(\mu \mathrm{mol} / \mathrm{mol})\end{array}$ & $\begin{array}{l}354.82 \pm \\
519.18\end{array}$ & $472.58 \pm 438.35$ & 138.68 & $0.011+$ & $0.037 \$$ \\
\hline
\end{tabular}

$+\mathbf{p}<0.05 ; \S \mathbf{p}<0.01$ 